\title{
SABERES EXPERTOS EN LA ENCRUCIJADA: RAZAS, ANTI/RACISMO Y CIENCIAS EN UNESCO 1949-1950
}

\author{
Ana Lucía Grondona \\ Universidad de Buenos Aires
}

http://dx.doi.org/10.5209/rev NOMA.2016.v47.n1.52405

\begin{abstract}
Resumen.- El presente artículo se propone estudiar, retomando diversos aspectos del Análisis Materialista del Discurso, una serie de discusiones de la inmediata posguerra que colocaron la cuestión racial y al racismo en el centro de la agenda de las ciencias (naturales y sociales) así como de los organismos internacionales. Antes que reponer y reproducir una imagen de coherencia u homogeneidad en estos debates, propondremos una lectura a contrapelo capaz de mostrar la articulación contingente de elementos de diversa procedencia, las contradicciones, las tensiones y, sobre todo, las luchas involucradas en ellos.

En un primer apartado presentaremos algunos aspectos generales de las discusiones en torno de la cuestión racial en la Segunda Posguerra y el papel que en ello tendrían UNESCO y las ciencias sociales. Luego, nos referiremos sintéticamente a los debates fascistas en torno de la cuestión racial para, en el siguiente apartado, desarrollar la primera de nuestras tesis: la existencia de una relación de diálogo/antagonismo entre la declaración de 1949 de UNESCO y los debates fascistas en torno de las leyes raciales entre 1935 y 1938 . A partir de ello, en la sección siguiente, desplegaremos nuestra segunda hipótesis, derivada de la primera: las discusiones de UNESCO además de dirigirse a un público general resultan de una disputa al interior de diversos campos científicos. En este tramo, analizaremos los vínculos entre ciencia y política que recorren los diversos documentos que conforman nuestro estudio. Finalmente, propondremos algunas reflexiones a modo de cierre.
\end{abstract}

Palabras clave.- saberes expertos- interdiscurso- antagonismo- cuestión racial- neutralidad científica

Abstract.- This papers focuses - resuming several concepts of Materialistic Discourse Analysis- on a series of discussions displayed immediately after the WWII around the issue of race and racism within the field of (natural and social) sciences and around different International organizations. Rather than reproducing an image of consistency or homogeneity of these debates, we propose a critical analysis capable of showing the contingent articulation of elements of diverse origin, contradictions, tensions and, above all, the struggles involved in them.

In the first section we present some general aspects of the discussions around the issue of race in the Postwar period and the role played in them by UNESCO and social sciences. Then we will synthetically refer to the fascist debates around the racial question in order to, in the next section, develop the first of our thesis: the existence of a relationship of dialogue / antagonism between UNESCO's declaration on race in 1949 and fascist debates around racial laws between 1935 and 1938. In the following section, we will display our second hypothesis, derived from the first one: UNESCO' $S$ discussions were not only targeted to the general public but also resulted from a dispute within different scientific fields. In this section, we will discuss the ways in which science and politics appear intertwined throughout the documents we have analyzed. Finally, we propose some concluding remarks.

Key words: expert knowledge- interdiscourse- antagonism- racial question- scientific neutrality 
El peligro que debemos evitar es transformarnos en guardianes o en cautivos de nuestros propios $y$ arbitrarios esquemas clasificatorios

Ashley Montagu (1972: 33).

\section{Introducción}

Una buena parte de los ejercicios contemporáneos del pensamiento crítico parecen concentrarse en la tarea de desmontar «narrativas». Quizás el ejemplo más palmario sea el de la perspectiva de la colonialidad del saber/poder en relación a las narrativas de la modernidad/modernización. Tras aquellos relatos, se ocupa de señalar la «nueva» crítica, se esconde siempre una mirada eurocéntrica y racista. Justamente, el presente artículo busca desestabilizar algunas "evidencias» presentes en este tipo de aproximaciones, actualmente hegemónicas en diversos medios académicos.

En términos «temáticos» presentaremos una serie de discusiones de la inmediata posguerra que colocaron la cuestión racial y al racismo en el centro de la agenda de los organismos internacionales en el momento mismo en que comenzaban a diseñar sus programas de modernización y desarrollo. Entendemos que estos debates, visitados ya por numerosos estudios reconstructivos, problematizan y muestran las tensiones de la «modernidad/modernización» como proyecto. Por una parte, implicaron una disputa en relación a las jerarquías Norte-Sur en la producción de «modelos civilizatorios», por otro lado disputaron la preeminencia de las ciencias naturales por sobre las sociales.

La perspectiva que adopta nuestro estudio, que combina una aproximación sociológica con el punto de vista del Análisis Materialista del Discurso ${ }^{1}$, no parte del análisis de "narrativas» ni de "racionalidades» entendidas como sistemas homogéneos o coherentes de producción de sentido. Por el contario, nuestro acercamiento a los documentos los interroga sobre heterogeneidades mostradas (por ejemplo, citación de otras voces) y sobre otras constitutivas que horadan la unidad imaginaria con la que cualquier texto se presenta (AuthierRevuz, 1984). Antes que reponer y reproducir ese imaginario de cohesión, proponemos una lectura a contrapelo capaz de mostrar la articulación contingente de elementos de diversa procedencia, las contradicciones, las tensiones y, sobre todo, las luchas. Así, la operación de desmontar narraciones (o, mejor, imaginarios) no arrojará como resultado una contra-narración sino la dispersión y complejidad de múltiples entrecruzamientos.

Luego de esta breve introducción, en un primer apartado presentaremos algunos aspectos generales de las discusiones en torno de la cuestión racial en la Segunda Posguerra y el papel que en ello tuvieron la Organización de las Naciones Unidas para la Educación, la Ciencia y la Cultura (UNESCO) y las

\footnotetext{
${ }^{1}$ Con esta expresión nos referimos a la perspectiva althussereano-foucaulteana iniciada por Michel Pêcheux y que hemos presentado en un trabajo colectivo (Fulanito et al, 2014).
} 
ciencias sociales ${ }^{2}$. Luego, nos refreiremos sintéticamente a los debates fascistas en torno de la cuestión racial para, en el siguiente apartado, desarrollar una de las dos tesis centrales del presente artículo: la existencia de una relación de diálogo/antagonismo entre la declaración de 1949 de UNESCO y los debates fascistas en torno de las leyes raciales entre 1935 y 1938 . A partir de ello, en la sección siguiente, desplegaremos nuestra segunda hipótesis, derivada de la primera: las discusiones de UNESCO además de dirigirse a un público general y pretender combatir la irracionalidad que conduciría al prejuicio racial (posición que suele caracterizarse como de un «racionalismo ingenuo») resulta de una disputa al interior de diversos campos científicos e interpela a diversos expertos que no estaban dispuestos a abandonar posiciones racistas/racialistas. En este tramo, el más extenso de nuestro trabajo, deberemos analizar los vínculos entre ciencia y política que recorren los diversos documentos que conforman nuestro estudio. Finalmente, propondremos algunas reflexiones a modo de cierre.

\section{UNESCO, las ciencias sociales y la cuestión racial}

Entre el 12 y el 14 de diciembre de 1949 en la ciudad de París se reunía un conjunto ecléctico de expertos con la misión de definir científicamente el concepto de «raza», evaluar el estado del conocimiento del tema y proponer líneas de investigación (UNESCO 1949c). Franklin Frazier figuró como el chairman del encuentro, Ashley Montagu ofició como relator, Ernest Beagle Hole, Juan Comas, Luis Aguiar Costa Pinto, Morris Grinsbereg, Humayun Kabir y Claude Levi-Strauss conformaban el grupo de expertos especialmente invitados ${ }^{3}$.

Esta iniciativa, sobre la que nos extenderemos, estuvo estrechamente vinculada al Departamento de Ciencias Sociales de UNESCO que se había puesto en marcha dos años antes. Entre los diversos proyectos que iba organizar esta repartición se destacaría el Tensions Project, que entre 19481952 reunió una serie de inquietudes frente a los conflictos y tensiones de la vida moderna, desde las psicológicas hasta, precisamente, las raciales.

Como resultados de estas líneas de trabajo de UNESCO entre 1949 y 1964 iban a producirse y circular múltiples libros y colecciones (vgr. «La cuestión racial ante la ciencia moderna»), así como materiales de divulgación para niños (What is race? Evidence from scientist) y varios artículos en la revista mensual del organismo, El correo de la UNESCO. En el presente artículo nos concentraremos en los primeros años de estas discusiones y debates (19491955) de las que participaron científicos de primera línea tanto de los países centrales (Lévi-Strauss, Gordon Allport, Max Horkheimer, Alfred Métraux, Otto Klinensberg, Franklin Frazier, Raymond Aron, Louis Wirth, T. H Marshal, Meleville Herskovits) como del Sur (Gilberto Freyre, Ruy Coelho, René Ribeiro, Arthur Ramos, Florestán Fernandes, Oracy Nogueira, Luis Aguiar Costa Pinto y Juan Comas, entre otros).

\footnotetext{
${ }^{2}$ Entre quienes, antes de nosotros, han trabajado sobre las iniciativas de UNESCO en torno de la cuestión racial están Gastaut (2007), Chloé (2007), Maio (2007, 2000); Müller-Wille (2007) Taguieff (1992), Hazard (2012) y Gil-Riaño (2014.)

${ }^{3}$ Jan Czeckanwski de Polonia y Joseph Skild de Suecia también figuraron entre los científicos invitados, pero no pudieron asistir por problemas de salud (Montagu, 1972: 3).
} 
Según ha señalado Marcos Chor Maio (2007) en las empresas enumeradas más arriba, el papel de América Latina resultó particularmente relevante. Por una parte, tres de los ocho firmantes de la primera declaración de las razas habían estudiado en Brasil. Por otra parte, el brasileño Arthur Ramos -actor clave en la organización de la primera reunión de expertos en 1949-, había sido nombrado ese mismo año director del Departamento de Ciencias Sociales. Ante su sorpresiva muerte, poco antes del mes de diciembre, fue reemplazado por el suizo Alfred Métreaux, quien, por cierto, había vivido en su infancia y temprana juventud en la Argentina ${ }^{4}$. Resulta destacable, asimismo, el dato que nos brinda Maio (1999: 150), según quien había sido el brasileño Gilberto Freyre el primer convocado para ocupar el cargo que en 1949 asumió Ramos. Asimismo, el uruguayo Jaime Torres se transformaba, a partir de ese mismo año, en el Director General del organismo.

A la circulación de estas y otras figuras latinoamericanas, debe sumarse el creciente financiamiento brindado al estudio sobre las relaciones raciales alrededor del mundo, sobre todo en Brasil. En particular, el trabajo del ya mencionado Gilberto Freyre había promovido una mirada no-racista sobre la negritud y su papel en la conformación nacional. Ese camino fue profundizado por los nacientes proyectos de institucionalización de la sociología y la antropología entre 1930 y $1940^{5}$; proceso del que participaron activamente muchos de los cientistas que actuarían en al ámbito de UNESCO: Donald Pierson, Roger Bastide, Emilio Willems y Meleville Herskovits, Claude LéviStrauss, Franklin Frazier. Luego de la conferencia general de Florencia de 1950, UNESCO lanzó una línea de investigaciones sobre las relaciones raciales en Brasil que, justamente, partía de estas colaboraciones previas y del «paradigma» propuesto por G. Freyre, que pensaba a aquél país como un ámbito de relativa democracia racial (Maio, 2000). Al respecto, en el prefacio de la publicación de la primera declaración sobre las razas en el International social science bulletin de 1950, Alfred Mêtreaux señalaba:

Las relaciones entre distintas razas no están necesariamente marcadas por tensión y hostilidad. América Latina, entre otros, es un continente en el que, al menos hasta hace pocos años, el sentimiento racial no estaba fuertemente desarrollado y el antagonismo entre gente de distinto color estaba lejos de exhibir el carácter brutal ejemplificado por diversos países anglosajones (...) Sin embargo, una mera descripción de tales relaciones amistosas y sus efectos no resultan suficientes para fines científicos. El objetivo es el de explicar los varios factores que en han creado en Sudamérica un espíritu de tolerancia racial que contrasta nítidamente con la intransigencia mórbida que se observa en otros medios sociales y culturales (Mêtreaux, 1950: 389).

En este sentido, la reunión de diciembre de 1949 a la que nos referíamos al comienzo de este apartado inauguraba, pero también retomaba una serie de discusiones previas. Según ha documentado extensamente Elazar Barkan

\footnotetext{
${ }^{4}$ Ver Prins y Krebs (2007).

${ }^{5}$ Ciertamente, la cuestión racial había sido un tema relevante en aquél país desde comienzos del siglo XX, por ejemplo bajo la impronta de Raimundo Nina Rodrigues, psiquiatra y antropólogo formado en el positivismo italiano de Cesare Lombroso. Sin embargo, a partir de la re-problematización de «la Nación» en la década del treinta, la cuestión racial había sido revisitada de nuevos modos.
} 
(1990) la confrontación entre posiciones racialistas/racistas y antirracistas en el campo científico se había desatado durante la década de 1930 y había tenido entre sus principales espadas a Franz Boas. En efecto, Barkan muestra cómo el antropólogo fue comprometiéndose, primero tímidamente y luego de un modo decidido, en diversas campañas que buscan la toma de posición de expertos estadounidenses y europeos contra los argumentos "científicos» enarbolados por el racismo nazi y fascista. En el camino iría encontrando diversas resistencias, como por ejemplo, el cuestionamiento de su «neutralidad» en virtud de su «condición» de judío (Barkan, 1990: 187). Otros interpelados se negaban a adherir públicamente a las posiciones de Boas no por falta de acuerdo con ellas -según Barkan la desvinculación entre «herencia racial» y actitudes/características/capacidades psicológicas y/o culturales era un hecho relativamente establecido en EE.UU- sino para evitar "controversias» en lo que entendían eran posiciones demasiado asertivas ${ }^{6}$. Por el contrario, en Gran Bretaña, las resistencias habían estado vinculadas a la relativa hegemonía de posiciones que aun asociaban los rasgos culturales a determinantes biológico-raciales.

Boas no fue, sin embargo, un luchador solitario. En sus diversas campañas se encontró y articuló con otros expertos que, cada uno por su parte, habían comenzado empresas análogas a la suya. Entre ellos, el checo Ignaz Zollschan, un médico que había llegado a reunir voluntades importantes alrededor de la causa del antiracismo científico, como el futuro Papa Pio XII, el Ministro de Relaciones Exteriores checo y el International Institute for Intelectual Cooperation (antecedente inmediato de la UNESCO). También resultaban coincidentes los trabajos de Alfred Haddon y Julian Huxley (primer Director General de la UNESCO) alrededor del manifiesto de 1936 We Europeans. A survey of racial problems que marcaba la conversión de Huxley hacia posiciones anti-racistas que cuestionaban la validez de la noción misma de «raza». Otros nombres, como el de Lucien Levy-Bruhl, Celestine Bouglé, Donald Young, Robert Mclver, Otto Klinenberg, L.C Dunn, Morris Grinenberg deben añadirse al listado de expertos involucrados en la disputa contra el racismo/racialismo científico por aquellos años.

Nos interesa, pues, concebir la reunión de 1949 como un nudo en una red de múltiples discusiones previas y posteriores que serían fundamentales para diversos campos científicos de posguerra, singularmente, para las ciencias sociales y, muy especialmente en América Latina?

El resultado dicho encuentro fue un documento que denunciaba que el concepto de raza había funcionado más como un mito que como un hecho científico. Ante esta atrevida afirmación, las respuestas y objeciones desde dentro y de fuera del campo experto no tardaron en llegar. A pesar de que el documento final había sido revisado y corregido por especialistas ajenos a la reunión de 1949- Handley Cantril, E. G Conklin, Gunnae Dahlberg, Theodosius Dobzhansky, L.C Dunn, Donald Hager, Julián Huxley, Otto Klinenberg, Wilbert

\footnotetext{
${ }^{6}$ Las críticas a la declaración de las razas de UNESCO de 1949/1950 volverán a poner sobre el tapete el mismo argumento.

${ }^{7}$ Al citado caso de Brasil deben agregarse las discusiones en torno del indigenismo de Juan Comas en México, sobre las que volveremos, e incluso los trabajos de Gino Germani. No podemos extendernos en este punto, referimos al lector a un trabajo previo sobre este punto (Fulanito, 2014)
} 
Moore, H.J Muller, Gunar Myrdal y Joseph Needham- UNESCO decidió hacer un segundo encuentro para analizar los resultados de la primera, que iba a concretarse poco después, en 1951.

Atendiendo a la red de discusiones en las que, desde nuestra perspectiva, se inscribe la declaración de 1949, no es un diálogo "de dos» lo que aquí queremos presentar. Nos interesa poner en relación los debates suscitados inmediatamente alrededor de la declaración de 1949/1950 (formulados de un modo explícito, como veremos) con una tercera voz que, aunque no explicitada, resulta -en nuestra hipótesis- constitutiva de las discusiones fomentadas por UNESCO. Nos referimos al denominado «Manifesto degli scienziati razzisti», un documento publicado en el Giornale d'Italia, el 15 de julio 1938, bajo el título «ll Fascismo e i problemi della razza» y reeditado poco después en el primer número de la revista La difesa della razza (5 de agosto de 1938), con la firma de diez científicos de muy diverso prestigio.

Indudablemente, los tres documentos ${ }^{8}$ en los que basamos primariamente nuestro análisis resultan de muy diversas condiciones de producción ${ }^{9}$. Por una parte, el manifiesto de los científicos fascistas marcó el inicio de las políticas raciales en Italia, luego de un complejo vaivén del régimen respecto de esta cuestión. La historiografía acuerda un papel primordial a Guido Landra en la redacción de este manifiesto $y$, fundamentalmente, a Benito Mussolini, cuyas ideas el primero había conocido en una entrevista organizada por el propagandista Telesio Iterlandi. Otras personalidades rutilantes de las ciencias racistas, como Lido Cipriani, habían jugado un rol secundario en la redacción del documento, mientras que figuras prestigiosas como Nicola Pende y Sabato Vico, habían adherido al escrito de mala gana ${ }^{10}$.

${ }^{8}$ En rigor trabajamos sobre la base de una constelación más extensa de documentos: AA.VV
(1938) "Razzismo Italiano» (traducción al castellano disponible en https://es.wikipedia.org/wiki/Leyes raciales fascistas 10/08/2015); UNESCO 1949 «Statement on Race. Meeting of experts on Race Problems»; UNESCO 1949 «Summary report (of the six meetings)»; UNESCO 1949 "Working paper of the Committee. 20 Jan. 1950.SS/CONF.1/3 »; UNESCO 1951 «Statement on the nature of race and race differences; by physical anthropologists and geneticists»; Montagu, Ashley (1972) Statement on race. An annotated elaboration and exposition of the four statements on race issued by the UNESCO; UNESCO 1952, The Race concept: results of an inquiry; salvo cuando se aclare lo contrario las traducciones al castellano fueron tomadas de UNESCO 1969 Cuatro declaraciones sobre la cuestión racial. Las referencias completas están al final.

${ }^{9}$ Desde la perspectiva del Análisis Materialista del Discurso las condiciones de producción resultan «un haz de procesos de diverso orden que abarcan dos instancias, que responden a dos órdenes de lo discursivo: (1) las condiciones de formulación (cf) de una secuencia discursiva - que involucran a su vez condiciones de producción (cp) y procesos de enunciación (ce) - y (2) las condiciones/ procesos de formación de los discursos (CF)». Desde este punto de vista, «al formular - producir texto, oral o escrito - el "sujeto enunciador" se coloca en el lugar de "fuente del sentido" y "dueño de su decir", olvidando que sus palabras están sujetas no solo a determinaciones de la materialidad lingüística y de la coyuntura sino también al orden del interdiscurso. Incorporar, como dimensión constitutiva de la investigación las Condiciones de Formación (CF) de los discursos significa pensar justamente - tanto en un plano teórico como en los modos de trabajar el archivo para la conformación de corpora - las relaciones del documento/conjunto de documentos con ese «exterior constitutivo» cuyos trazos se inscriben al interior de los textos» (Fulanito et al., 2014: pp. 43-44). En este artículo presentamos esta perspectiva en funcionamiento. Por ello, remitiremos las definiciones teórico-metodológicas en nota al pie, salvo cuando sea estrictamente necesario incorporarlas al cuerpo del texto.

10 Ver, por ejemplo Giorgio Israel y Pietro Natasi (1998) o Francesco Cassata (2008). Desarrollamos más extensamente esta cuestión en Fulanito (2015). 
Por su parte, la declaración de las razas de 1949 (publicada con correcciones en $1950^{11}$ ) se nos presenta como el canto del cisne de un breve y agitado periodo en el que UNESCO albergó, al mismo tiempo, una corriente de «recomposición» de un universalismo confiado en la primacía de la razón sobre el prejuicio y otra que, mucho más pesimista respecto del papel de la ciencia, estaba dispuesta a llegar hasta el final en el análisis crítico de una sociedad y una cultura en la que el Holocausto había sido posible ${ }^{12}$. En ese marco, ciertas jerarquías usualmente estables resultaron vulnerables y vulneradas: la primacía de los países "desarrollados» o «modernos» frente a los atrasados, por una parte, y la preeminencia de las ciencias naturales por sobre las sociales, por la otra $^{13}$. La presencia de cientistas sociales y del Sur (India, México, Brasil) en la reunión de 1949 no resulta una anécdota.

En relación con la primacía de los cientistas sociales en el documento de 1949/1950, el primer draft de la declaración de 1949 hablaba de los consensos alcanzados por los antropólogos (Antropologists), mientras que en la versión publicada en 1950 se reemplaza esta palabra por "Scientists» ("Savants» en francés, «Sabios», en castellano). En efecto, aunque Juan Comas y Ashley Montagu (señalado como el alma mater del documento final) provenían de la antropología física (más próxima al campo de la biología), buena parte de los participantes, convocados por el antropólogo brasileño Arthur Ramos ${ }^{14}$, habían construido sus trayectorias en el ámbito de las ciencias sociales.

Por su parte, el documento de 1951, que se proponía rectificar diversos aspectos del primer documento de UNESCO, se presentaría, por el contrario, como una comunicación producida en nombre de los antropólogos físicos y genetistas. Entre los asistentes, no se consigna ni un experto latinoamericano. Tal como veremos, esta segunda declaración sobre la naturaleza de las razas y las diferencias raciales representa, respeto de la primera declaración, un ejercicio de atemperación y, en buena medida, de «regreso al orden».

Ahora bien, este «regreso» tampoco careció de polémicas. Muy por el contrario, la declaración sobre las razas de 1951 también despertó debates y discusiones. Las autoridades del organismo consultaron a 95 especialistas sus opiniones sobre este segundo documento y publicaron una síntesis de ellas en 1952. Ese texto mostró a las claras que el campo de debate científico estaba lejos de aceptar «sin más», las posiciones avanzadas por UNESCO, incluso bajo

\footnotetext{
${ }^{11}$ Trabajamos con una transcripción de las discusiones de 1949 en la que figura el documento acordado y con las ediciones en inglés, francés y castellano de la declaración corregida y publicada en 1950.

${ }_{12}$ En su tesis, Sebastián Gil-Riaño (2014) delimita dos «narrativas de redención» contrapuestas en los debates de UNESCO. Por una parte, una narrativa anticipatoria de la redención, en la que la cultura moderna y tecno-científica promete acercar a las naciones y emancipar a las naciones subdesarrolladas de la ignorancia y la pobreza. Por otro lado, una narrativa nostálgica que interpelaba a preservar la pureza de las así llamadas «culturas primitivas». No compartimos esta caracterización. Por una parte, como hemos indicado más arriba el concepto de «narrativa» resulta problemático. Por otro lado, entendemos que la hipótesis de Gil-Tiaño exagera la «inocencia» tanto de los documentos analizados como de los expertos en cuestión. En consecuencia, subestima la politicidad de las discusiones. Intentaremos desarrollar esta hipótesis a lo largo del artículo.

${ }^{13}$ Compartimos esta idea con Giraudo y Martín-Sánchez (2013).

${ }^{14}$ Se trataba, como hemos dicho, del jefe del Departamento de Ciencias Sociales, quien moría prematuramente en 1949 y fue reemplazado por Robert C. Angell en la organización de la reunión.
} 
una forma mucho menos «asertiva» que la que presentaba el documento de 1949/1950.

Lo expuesto hasta aquí nos permite presentar una de las hipótesis centrales de este trabajo. A diferencia de buena parte de la literatura circulante sobre las declaraciones de UNESCO -que aquí analizaremos y que suelen caracterizarlas como intentos algo ingenuos de rectificar las posiciones racistas y a/anticientíficas de la opinión pública o de ciertas ideologías políticas-, nuestro trabajo intenta mostrar que, por el contrario, existe una doble destinación de las declaraciones, hacia «el público general», pero también al interior del campo de especialistas. Esta doble destinación delimita un contradestinatario «interno» al campo científico (aquellos que justificaban científicamente el racismo) que, justamente, se busca excluir, con el que se busca antagonizar de un modo radical y a quienes se coloca, por ello, en el lugar de lo no-científico. Desde este punto de vista, como veremos, las posiciones de 1949/1950 pierden su apariencia de ingenuidad y muestran un rasgo netamente político. No se trataría, pues, solamente de desterrar la ignorancia que conduce al racismo, sino de disputar quien/cómo se habla en nombre de la ciencia y el complejo vínculo entre ciencia y política.

En el apartado que sigue presentaremos el manifiesto de los científicos italianos de 1938 que, desde nuestra hipótesis, funciona como dominio interdiscursivo de memoria ${ }^{15}$ y campo de adversidad de la declaración de UNESCO de 1949. Luego, pondremos en relación ("punto por punto») ambos documentos. A continuación de ello, compararemos los modos de disponer las distintas voces y puntos de vista en los tres documentos (1938-1949-1951), a fin de extraer algunas conclusiones respecto de la relación entre ciencia/política que se articula en cada uno de ellos.

\section{La cuestión racial y las memorias del fascismo}

Tal como se ocuparon de denunciar y de pensar autores como Michel Foucault - los teóricos de la Escuela de Frankfurt el despliegue de la máquina de aniquilamiento nazi y fascista no operó ni al margen ni -mucho menos- contra la «racionalidad occidental». Las distintas ciencias (biológicas, sociales, administrativas) jugaron variados y destacados papeles. Ello resulta notable en el caso de la delimitación del "problema racial».

Los análisis sobre esta cuestión han privilegiado el modo en que el cálculo, el despliegue científico y el saber técnico se articularon bajo el régimen autoritario alemán. Sin embargo, por diversas cuestiones, será, en nuestro caso, el régimen racista italiano el que nos interesará presentar como región del

\footnotetext{
${ }^{15}$ La perspectiva con la que trabajamos propone una organización de corpora a partir de series de documentos cuyas vinculaciones establece el investigador a partir de ciertas huellas textuales (que deberán mostrarse, ver siguiente apartado) y que exceden la referencia/remisión explícita de los textos. Operativamente, a lo largo de la investigación, se recortan distintas zonas del archivo (dominios interdiscursivos) atendiendo a criterios inmanentes al proceso de indagación. Los documentos incluidos en cada recorte pueden responder a diversos criterios de periodización, temáticos, de género discursivo, etc. Ellos son resultado y no punto de partida del trabajo.

En este artículo, particularmente en el apartado que sigue, intentaremos mostrar los debates fascistas en torno de las leyes y normativas raciales entre 1935 y 1938 funcionan como dominio interdiscursivo de memoria en relación a las discusiones de UNESCO entre 1949 y 1951.
} 
interdiscurso $^{16}$ interviniente en las discusiones de UNESCO de 1949/1950 y de 1951. Existen diversos motivos que justifican este énfasis. Por una parte, se trata de una zona menos visitada del archivo, hecho que ya le confiere cierto interés. En segundo lugar, el trabajo de mayor aliento en el que se inscribe el presente trabajo parte de una pregunta por la denominada «sociología latinoamericana de la modernización» y en particular por el trabajo de Gino Germani, cuyo antifascismo -según se ocupó en señalar su hija Ana (Germani, 2004)- puede leerse como una «invariante» en sus producciones. Fundamentalmente, sin embargo, entendemos que la relación entre ciencia, política y racismo en Italia tuvo rasgos equiparables a los de las discusiones UNESCO y diversos a los del nazismo alemán.

Tal como hemos explicado en otro trabajo (Fulanito, 2015) el fascismo tuvo una relación singularmente oscilante con la cuestión racial. A diferencia del nazismo, en cuya matriz ésta ocupaba un lugar nodal, constitutivo e incluso fundacional, en el caso italiano la intensidad de los procesos de discriminación y exclusión variaron en relación a la coyuntura política y geopolítica. Carece, pues, de la coherencia que suele adjudicarse a la ideología racista del nazismo. Las políticas raciales italianas desde 1935 combinaron un conjunto heterogéneo de perspectivas que abarcaron desde el catolicismo tradicional antisemita hasta perspectivas más biologizantes particularmente inquietas por el meticciato.

A pesar de la centralidad de la ratio política en el proceso que describimos, hubo lugar para múltiples injerencias de diversos saberes expertos. La puesta en marcha de una política racial más o menos sistemática en la península en 1938 -en las colonias había comenzado en 1935- estuvo precedida por el denominado "Manifiesto de la Raza», un documento firmado por 10 científicos, publicado en 1938 y que luego sería reafirmado por el Gran Consejo Fascista. Esta declaración era la antesala de las denominadas «leyes raciales» ${ }^{17}$.

El «Manifiesto de la Raza» trazaba una distinción fundamental entre las razas mediterráneas, las orientales, las africanas y las semitas. Se aclaraba, en particular, que los judíos no pertenecían a la raza italiana, pues era ésta la única población que no se había asimilado. El documento se oponía, así, a las teorías de Giussepe Sergi hasta entonces preponderantes -que planteaban el origen único de la especie humana, hipótesis que retomaría UNESCO. Más en general, el texto objetaba las perspectivas mediterraneistas ${ }^{18}$ y sostenía, por el

\footnotetext{
${ }^{16}$ En este artículo trabajamos con la definición de interdiscurso como «cuerpo de huellas como materialidad discursiva, exterior y anterior a la existencia de una secuencia dada, en la medida en que esa materialidad interviene para constituirla» (Pêcheux, 2012: 145-146). Para mayor desarrollo de esta noción, ver Fulanito et al. (2014).

17 Esta legislación comenzó recortando, en decretos del mes de julio de 1938, el acceso a instituciones educativas, universitarias, académicas y científicas a profesores judíos. Luego, prohibieron la circulación de textos en los que hubieran participado autores judíos, se revocó la ciudadanía otorgada a los judíos extranjeros después de 1919, prohibieron los matrimonios mixtos, la participación en cualquier nivel de la administración pública y en el Partido Nacional Fascista (PNF) y limitaron el derecho a la propiedad privada, al ejercicio libre de la patria potestad y de las más diversas profesiones.

${ }^{18}$ Esta perspectiva destacaba los logros de la raza «mediterranea», un grupo racial originario de Italia y el norte del Mediterráneo. Las antiguas civilizaciones (etruscos, griegos, romanos) clásicas fueron un producto de esta raza, particularmente dotada de rasgos intelectuales y creativas. Los «mediterranistas» despreciaban la rudeza y la superstición aria y, en consecuencia se contraponían a los «nordicistas».
} 
contrario, que la población italiana era en su mayor parte aria. Ello no sin ambivalencia, puesto que, al mismo tiempo, se insistía en las singularidades asociadas a la «romanidad», un mito cuidadosamente cultivado por Benito Mussolini. La conclusión programática fundamental del manifiesto era que los italianos no debían mezclar su sangre con la de razas inferiores. Asimismo, se los invitaba a proclamarse «abiertamente racistas» y a que la cuestión del racismo fuera tratada desde un punto de vista «puramente biológico», "sin intenciones filosóficas o religiosas».

Las posiciones raciales después de 1938 tuvieron diversos canales de difusión. Sin embargo, se destaca el rol de la revista cuasi-oficial dirigida por Telesio Interlandi, La difesa della razza ${ }^{19}$; órgano fundamental de propaganda racista que se caracterizó por combinar divulgación científica y polémicas altisonantes. Ahora bien, desde la perspectiva de historiadores contemporáneos, como G. Israel (1998) y R. Maiocchi (1999), otros científicos de mayor trayectoria también habrían cumplido, incluso antes de 1938, un papel importante en el despliegue de la versión italiana de las políticas raciales. En particular, la avanzada sobre África había resultado una circunstancia propicia para la emergencia de nuevos problemas, saberes y discursos en sintonía con el racismo de corte biológico que hegemonizaría el discurso fascista en 1938 (Maiocchi, 1999). Según sintetiza Gustavo Vallejo (2012), desde 1905 Italia contaba con una "antropología colonial» dedicada a escudriñar las especificidades de la alteridad nativa. Esta antropología de Estado había contado con la participación activa, entre otros, de Corrado Gini, como presidente del COMITATO ITALIANO PER LO STUDIO DEI PROBLEMI DELLA POPOLAZIONE. Francesco Cassata $(2006 \mathrm{a}, 2006 \mathrm{~b})$ ha producido diversos trabajos que toman alrededor de la figura del famoso demógrafo, a quien no duda en caracterizar a como un racista, aunque más sutil que, por ejemplo, $\mathrm{T}$. Interlandi (Cassata 2006a: 14).

Ahora bien, resulta fundamental, a nuestros fines, comprender que los expertos vinculados a la delimitación científica de la cuestión racial - en particular los más destacados- siguieron actuando aun mucho después del fin de la Segunda Guerra. En esa trayectoria posterior no necesariamente mermaron la radicalidad de sus posicionamientos. Asimismo, muchos de ellos hicieron de UNESCO su principal antagonista. Gini, por ejemplo, colaboró años después, en la década del sesenta, con un núcleo de expertos que polemizaban con las posiciones anti-racistas de las declaraciones de 1949/1950 y 1951. Éste núcleo se concentró alrededor de la revista académica Mankind Quarterly. El demógrafo realizó, en el nuevo contexto, un llamamiento a una «guerra de guerrillas» (Cassata, 2006b: 371) contra los nuevos discursos «ideológicopolíticos de matriz anglosajona».

Por otro lado, esta guerra de guerrillas, que debía librarse en nombre de la ciencia objetiva, también transcurrió a través de las organizaciones trasnacionales de expertos. Tal fue el caso del enfrentamiento entre el viejo INSTITUTE INTERNACIONAL DE SOCIOLOGIE (que acogía a personajes tan dudosos como Hans Freyer), presidido por C. Gini entre 1950 y 1963 y la INTERNACIONAL SOCIOLOGY ASSOCIATION, creada por UNESCO y cuyo primer presidente fue Louis

\footnotetext{
${ }^{19}$ Además de la bibiografía ya referida, cabe mencionar en este punto los trabajos de Valentina Pisanty (2007) y de Sandro Servi (2005) sobre la revista.
} 
Wirth (autor, recordemos, de The ghetto y referente de la lucha anti racista en los Estados Unidos).

En el apartado que sigue intentaremos mostrar el diálogo o, en rigor, la disputa, no explicitada, entre la declaración de UNESCO sobre las razas de 1949/1950 y la avanzada del racismo cientificista italiano, cuyas posiciones no sólo seguían circulando al momento de la reunión de París, sino que lo harían por varios años más.

\section{La declaración de 1949/1959 como una contraofensiva}

El primer punto de la declaración de los científicos fascistas de 1938 sostenía:

1. Las razas humanas existen. La existencia de razas humanas no es una abstracción de la mente, sino que corresponde a una realidad fenoménica, material, perceptible con nuestros sentidos. Esta realidad está representada por las masas, casi siempre impresionantes, de millones de hombres similares por las características físicas y psicológicas que se han heredado y continúan heredándose ${ }^{20}$ (AA.VV, 1938: 1, énfasis nuestro).

La declaración de UNESCO de 1949/1950 responde de diversos modos a esta afirmación. Por un lado, este último documento sostenía que «los sabios están de acuerdo en reconocer que la humanidad es una y que todos los hombres pertenecen a la misma especie, la del Homo sapiens» (UNESCO, 1969a:31). La unicidad de la especie humana sería, en efecto, uno de los aspectos subrayados por UNESCO ${ }^{21}$, hecho que, además, legitimaba la existencia objetiva de una ética de la fraternidad humana comprobada por "las investigaciones biológicas» (punto 15). Junto con esta aseveración, uno de los aspectos más controversiales de la declaración sería la que indicaba:

Para todos los efectos prácticos, la raza no es tanto un fenómeno biológico como un mito social. Es un mito que ha creado una enorme cantidad de daño humano y social (UNESCO 1949a: 4; traducción y énfasis nuestros).

La literatura coincide en señalar la huella de Ashley Montagu en este cuestionamiento radical al uso del concepto de raza, pues el autor había adelantado posiciones muy semejantes en trabajos anteriores ${ }^{22}$. En la reescritura del documento inmediatamente posterior a la reunión de 1949, cuyo

\footnotetext{
${ }^{20}$ Sigue «Decir que hay razas humanas no significa necesariamente que hay razas humanas superiores o inferiores, sino sólo que existen diferentes razas humanas.» En todos los casos, hemos trabajado con la traducción disponible en traducción disponible en https://es.wikipedia.org/wiki/Leyes raciales fascistas 10/08/2015

${ }^{21}$ Así«Lo esencial es la unidad de la humanidad, tanto desde el punto de vista social como desde el biológico. Reconocer este hecho y regir en consecuencia la propia conducta es el deber principal del hombre moderno» (UNESCO, 1969a:35). Incluso el documento hacía de Charles Darwin una cita de autoridad respecto de la unicidad de la especie humana.

${ }^{22}$ Las actas de la reunión, publicadas por UNESCO, sugieren lo mismo (UNESCO 1949b). La literatura señala el texto de Montagu Man's Most Dangerous Myth: The Fallacy of Race, (publicado por la editorial Harper en 1942), como un antecedente clave para las posiciones de UNESCO en 1949/1950. Por cierto, este libro retomaba la crítica que Julian Huxley y A.C. Haddon habían realizado a la noción de «raza» en We Europeans: A Survey of Racial Problems Hardcover de 1935, texto al que nos referimos más arriba.
} 
resultado fue el documento oficial publicado en 1950, esta afirmación se matizaría anteponiéndole una frase que señalaba la necesidad de distinguir entre «la raza como hecho biológico y como mito». Esta atemperación (que reconocía y distinguía más claramente la raza como hecho-científico) no contuvo, sin embargo, las múltiples respuestas polémicas a la declaración, muchas de las cuales reeditarían el argumento del párrafo con el que comienza este apartado, que apunta a "la evidencia» de las diferencias raciales como algo corroborable inmediatamente por los sentidos. Volveremos sobre esta cuestión.

También en relación al primer punto de la declaración de los científicos fascistas, que refería a «hombres similares por las características físicas y psicológicas» heredadas, el documento de 1949/1950 construía un fuerte y taxativo argumento respecto de que la clasificación del antropólogo «jamás» incluye características mentales ni emocionales. Para ello, el documento de UNESCO se valía de una cita de Confucio que establecía que tales diferencias no respondían a la naturaleza, sino a las costumbres, a la organización social. Esta afirmación, tal como veremos, sería relativizada en la declaración de 1951.

En el segundo punto del manifiesto fascista de 1938 se sostenía la existencia de grandes y pequeñas razas «por ejemplo, los nórdicos, los mediterráneos, los dinárdicos, etc., caracterizados por un mayor número de particularidades comunes. Estos grupos son desde el punto de vista biológico las auténticas razas, cuya existencia es una verdad evidente» (AA.VV., 1938: 1). Nuevamente, contrariando estas evidencias, en 1949/1950 los sabios sostenían que "[l]as razas humanas han sido clasificadas -y lo son todavía- de distinto modo según los antropólogos» (UNESCO 1969a, punto 7: 32, énfasis nuestro). En este sentido, aunque la mayoría de los expertos organizaba la humanidad en tres grandes grupos (mongoloide, negroide, caucasoide) se señalaba que las categorías y sus fronteras eran móviles, pues «los fenómenos biológicos que, hasta cierto punto, han sido cristalizados en esta clasificación tienen un carácter dinámico y no estático» (ídem). Las divisiones no habían sido las mismas en el pasado y había «motivos para creer que cambiarán todavía en el futuro» (ídem). Asimismo, reconocía un sinfín de subgrupos que no habían sido siquiera estudiados (ídem, punto 8: 32).

En un texto publicado por Ashley Montagu (por primera vez) en 1951 con el objeto de difundir las declaraciones de la raza, el alma mater del documento de 1949/1950 volvía sobre el punto en cuestión. Según explicaba el antropólogo, la clasificación en distintos grupos varía «ampliamente de acuerdo a las predilecciones de quien clasifica» (Montagu, 1972: 32). Distintos "escritores» habían reconocido desde tres a más de cien razas. Asimismo, las subdivisiones y criterios para la clasificación variaban (color de piel, tipo de cabello, forma del cráneo, frecuencia de genes, etc.). Lo mejor era, pues, simplemente «describir poblaciones». Desde la perspectiva del experto, «aunque nuestras clasificaciones puedan resultar interesantes, debemos tener cuidado de no tomarlas demasiado en serio» (ídem: 33).

Ha llamado nuestra atención la escasa ponderación de este argumento de A. Montagu y de la declaración de UNESCO de 1949/1950. Afirmar de un modo tan taxativo la precariedad de categorías tan naturalizadas como la de la raza merecería, a nuestro juicio, una reflexión más cuidadosa. En definitiva, el 
experto afirma la continuidad de la especie humana (como dato) y la producción de divisiones al interior de ese continuum como un hecho histórico $y$, por ello, susceptible de transformación. Así, las categorías con las que organizamos "lo biológico» lejos de expresar una verdad última "de la cosa» (precisamente, la naturaleza humana) la producirían de un modo arbitrario y peligroso. Desde nuestra perspectiva, un desafío tan abismal al pensamiento biologicista-determinista está en consonancia con, por ejemplo, discusiones contemporáneas respecto de las categorías del dimorfismo sexual (desarrolladas extensamente por Judith Butler). La objetividad de «la raza» como criterio de diferenciación vigente en 1949/1950 no debiera subestimarse, más aún si tomamos en cuenta que la sentencia contra la segregación en las escuelas del sur de los EE.UU (Brown vs Board of Education) no llegaría sino hasta cuatro años después ${ }^{23}$.

Pues bien, retomando la puesta en relación de la declaración de 1949/1950 y el manifiesto de los científicos fascistas, observamos que el tercer punto del documento de 1938 insistía en el carácter puramente biológico del concepto de «raza», que diferenciaba de «pueblo» y «nación»; estos últimos términos remitían, por su parte, a dimensiones históricas, lingüísticas y religiosas de la identidad colectiva. Sin embargo, se aclaraba que estaban vinculados con el componente biológico racial, "base de las diferencias entre los pueblos y las naciones» (AA.VV 1938: 1). Así, la diferencia entre italianos, franceses, alemanes y turcos no se reducía a matices en la lengua o la historia, sino también a divergencias en la constitución biológica. Contraponiéndose, nuevamente, a estas afirmaciones, el documento de 1949/1950 (y también en el de 1951) se sostenía que «los grupos nacionales, religiosos, geográficos, lingüísticos o culturales no tienen por qué coincidir necesariamente con los grupos raciales y los aspectos culturales de estos grupos no tienen ninguna relación genética demostrable con los caracteres propios de la raza ${ }^{24}$ » (UNESCO 1969a, punto 6: 32). Se intentaba desmontar, así, la explosiva asociación de raza-pueblo y raza-nación.

Los argumentos expuestos también horadaban la evidencia del cuarto, quinto y sexto punto de la declaración fascista según la cual la población italiana era aria y cuyo origen partía «esencialmente de elementos de aquellas mismas razas que componen y compondrán el tejido perpetuamente vivo de Europa» (AA.VV 1938, punto 4, : 1). En este sentido, los científicos del régimen habían sostenido, a contramano de los expertos de UNESCO y su énfasis en la precariedad de las fronteras raciales, que «los cuarenta y cuatro millones de

\footnotetext{
${ }^{23}$ El trabajo de A. Hazard (2012) analiza minuciosamente las diversas reacciones de la prensa y de distintas organizaciones de la sociedad civil en los EE.UU en relación a las declaraciones de UNESCO. Por su parte, el trabajo de P. Duedahl (2008) enfatiza su recepción por parte de militantes de los derechos civiles como el Reverendo Jesse Jackson y su papel en las batallas legales estadounidenses contra la segregación. Concretamente, tanto la decisión de la corte contra la separación en las escuelas en 1954 como la declaración de la inconstitucionalidad de la prohibición de matrimonios mixtos tomaron las declaraciones de UNESCO como legitimación científica.

${ }^{24}$ En el documento de 1951 la frase se reformulaba sin referencia a la dimensión genética: «los grupos nacionales, religiosos, geográficos, lingüísticos y culturales no coinciden necesariamente con los grupos raciales, y los aspectos culturales de estos grupos no tienen ninguna relación demostrable con los caracteres propios de la raza» (punto 3 ).
} 
italianos de hoy se remontan en su gran mayoría a las familias que han vivido en Italia durante al menos un milenio» (ídem, punto 5: 1).

Atendiendo a esta fijeza, en el sexto punto se afirmaba la existencia de "una pura "raza italiana»" sostenida en "el purísimo parentesco de sangre que une a los italianos de hoy a las generaciones que pueblan Italia desde hace milenios. Esta antigua pureza de sangre es el mayor título de nobleza de la nación italiana». Seguramente, esta caracterización podría incluirse en la crítica que realizaban los expertos de 1949 al «abuso del término» a partir del cual «muchas colectividades nacionales, religiosas, geográficas o culturales» habían sido consideradas «razas» (UNESCO 1969a, punto 5: 32).

En el octavo punto la declaración fascista de 1938 caracterizaba como «peligrosas» las teorías que sostenían «el origen africano de algunos pueblos europeos y que incluyen en una común raza mediterránea a pueblos camitas y semitas, estableciendo relaciones y simpatías ideológicas absolutamente inaceptables» (AA.VV 1938: 1). El noveno punto, volvía a subrayar la ajenidad entre los italianos y los judíos. A estas afirmaciones se opondrían, una vez más, los expertos de UNESCO al postular la unidad de la especie humana y, puntualmente «el mismo origen» de toda la especie Homo Sapiens que habría generado diversos grupos humanos a partir del «mismo tronco» (UNESCO 1969a, punto 1: 31$)^{25}$.

El décimo punto del documento de 1938, por su parte, interpelaba a mantener las características físicas y psicológicamente puras de la raza aria y evitar la mezcla con otras. Esta fue otra de las cuestiones rebatidas en la declaración de $1949 / 1950$ según la cual «todos los hechos que han podido reunirse referentes a los cruzamientos de razas comprueban que no han cesado de producirse desde los tiempos más remotos» y que «jamás ha podido comprobarse que los cruzamientos de razas lleven consigo efectos biológicos nefastos» (UNESCO 1969a, punto 13: 34). En consecuencia, se descartaba toda «justificación 'biológica' para prohibir el matrimonio entre individuos pertenecientes a grupos raciales diferentes» (ídem).

En el recorrido de los párrafos anteriores hemos mostrado que la declaración de UNESCO 1949/1950 funciona como una respuesta (no explícita, pero «punto por punto») al manifiesto de los científicos fascistas de 1938. En este sentido, más allá de que enunciativamente se construya un destinatario «lego» (las masas, el público, la opinión pública, etc.) el discurso, indudablemente también se dirige a los científicos racistas que participaron en los proyectos autoritarios europeos y que seguían circulando. Las comillas en 'biológica' en la cita del párrafo anterior refuerzan nuestro argumento, pues marcan una distancia respecto de quienes sostienen posiciones -en ese caso- contrarias al mestizaje en nombre de la biología. Ese tipo de enunciados no corresponderían, pues, a la biología (sin comillas). Así una de las dimensiones fundamentales de la disputa que hemos reseñado es por quien ocupa, legítimamente, el lugar de enunciación de la/s ciencia/s. Ocurre, sin embargo, que esta disputa funciona de diversos modos en el documento de 1949/1950 y en el de 1951. A partir de

${ }^{25}$ Por cierto este es uno de los núcleos de la disputa de los antirracistas en la segunda posguerra. Otro ejemplo notable de esta centralidad aparece en «The Races of Mankind,» de Ruth Benedict y Gene Weltfish, y luego en la animación de 1946 dirigida por Robert Cannon a partir de dicho panfleto («The Brotherhood of Man»). 
estas diferencias, mostraremos que el último implica un cierto «regreso al orden» o incluso un "repliegue» respecto de las posiciones avanzadas en $1949 / 1950^{26}$.

\section{¿Inocencia racionalista o disputas por la «verdad científica»?}

Entre los análisis de las declaraciones sobre la raza de UNESCO de 1949/1950 y 1951 se destaca particularmente el de Pierre-André Taguieff (1992). Nuestra propia indagación, sin embargo, difiere con este estudio en un punto relevante: la identificación de los «interlocutores» con los que ambos textos discuten y en nombre de quién/qué se lleva adelante esta discusión. Ambas cuestiones, como veremos, están íntimamente ligadas. A fin de desarrollar nuestro punto de vista deberemos dar un rodeo y analizar los modos en que tanto en los documentos de UNESCO como en el de los científicos fascistas de 1938 se ponen en escena distintas voces. Veamos.

Tanto en el manifiesto de los científicos de 1938, como en las declaraciones de UNESCO escasean las delimitaciones de una primera persona del plural que delimite claramente la voz y el punto de vista de los firmantes. En los casos en que aparece la primera persona (del plural) suele ser con un alcance universal o como generalización. La primera persona como modo de delimitación del colectivo firmante de los documentos aparece en las declaraciones de UNESCO tan sólo hacia el final ${ }^{27}$, justo antes de listar los 5 puntos de acuerdo sobre la cuestión de las razas a las que, en cada caso, habían arribado los científicos reunidos:

[C]reemos útil exponer de manera formal lo que, científicamente, se ha establecido sobre la cuestión de las diferencias entre individuos y entre grupos (UNESCO 1969a, punto 15: 35; se repite en UNESCO 1969b, punto 9: 45).

Observamos otros modos de delimitación de distintos puntos de vista presentes en cada documento. Tal como indicamos más arriba, en una primera versión, la de diciembre de 1949, el texto comenzaba sosteniendo una serie de acuerdos que «[l]os antropólogos han alcanzado», mientras que en la reescritura final del documento esta expresión se sustituiría por «Scientist» (científicos en inglés) ${ }^{28}$. Otras expresiones que delimitan voces son: «[d]esde el punto de vista biológico»; "un antropólogo», "Las investigaciones científicas de los últimos años», "los datos científicos», "la evidencia», "estudios biológicos». Por su parte, en el documento de 1951 también aparecen asignaciones de enunciados a «los antropólogos», «los psicólogos», «los biólogos», «el público general»,

\footnotetext{
${ }^{26}$ Según la bibliografía especializada esta atemperación fue resultado de las múltiples polémicas que despertó la declaración, fundamentalmente en la prestigiosa revista especializada Man. Por otra parte, una serie de científicos comprometidos con el anti-racismo (como Margaret Mead) alertaron a A. Métraux respecto del escaso prestigio de A. Montagu tenido por un polemista sin sustancia que buscaba tan sólo acrecentar su fama (Deuadahk, 2998: 14).

27 En este final también aparece un uso de la primera del plural que interpela al lector: «Examinemos ahora las incidencias de todas estas consideraciones sobre el problema de la igualdad entre los hombres» (UNESCO 1969a, punto 15: 35), que en 1951 se reformula como sigue: «consideremos la aplicación de todos estos datos al problema de la igualdad entre los hombres», UNESCO 1969b, punto 8: 45).

${ }^{28}$ En la versión francesa esta palabra se tradujo como«Savants» y en la castellana como «Sabios».
} 
«la genética», «especialistas en antropología física y genética». Por cierto, una singularidad del documento de 1949/1950 es que aparecen formas del discurso directo mediante citas textuales de Confucio (UNESCO 1969a: 33), de Darwin (ídem: 35) y de W.E Castle (UNESCO 1949a: 4) ${ }^{29}$.

Resulta significativo el hecho de que en el manifiesto de la raza de 1938 no abunden delimitaciones análogas a las que marcamos en el párrafo precedente. Por el contrario, el juego de voces más explícitamente marcado aparece en el punto siete y de un modo singular: Allí se sostiene que «frecuentísimo ha sido siempre en los discursos de il Capo la referencia a los conceptos de raza» (AA.VV, 1938: 1). Se trata, en efecto de una voz netamente política (en un sentido institucional) que, sin embargo, colabora para la construcción de un discurso científico legítimamente italiano, que según se afirma, deberá mantener «un punto de vista puramente biológico», sin «intenciones filosóficas o religiosas» (ídem). En este juego de demarcaciones aparecen otras perspectivas con las que se discute, fundamentalmente, «las teorías del racismo alemán». Aunque la voz italiana deberá orientarse en la dirección ario-nórdica no por ello sostendrá posiciones como «que los italianos y los escandinavos son la misma cosa». Más allá de los debates puntuales de aquella coyuntura, que hemos abordado en otro trabajo (Fulanito, 2015), nos interesa subrayar esta presencia en el documento de 1938 de voces que introducen una ratio (geo)política en la delimitación de una cuestión (que se presenta como) científica.

Justamente, uno de los únicos puntos de "consenso experto» del debate de posguerra sobre la cuestión racial apunta a la necesidad de desterrar aquel modo de entrecruzamiento entre ciencia y política. El pecado de la «propaganda» figura entre las acusaciones que más circulaban entre los expertos racistas y los anti-racistas.

Pues bien, retomando el análisis precedente, observamos que en contraste con el raleo de la delimitación de la voz del enunciador a partir del uso del yo/nosotros que observamos en los tres documentos, ausencia atribuible -en parte- a las constricciones de los géneros y formatos discursivos en cuestión, resulta llamativa la abundancia de marcas de la primera persona del plural en el prefacio a la declaración de UNESCO de 1951 que insisten en delimitar al colectivo de firmantes: "hemos estado de acuerdo» (UNESCO 1969b: 38), «todos nosotros estimamos» ( ídem: 39), «hemos reconocido», «hemos evitado prudentemente», "estamos de acuerdo», «hemos coincidido» y «tuvimos la suerte de contar» (ídem). Interesa subrayar aquí que esta voz se recorta en el prefacio de 1951 en contraposición con otras que aparecen citadas; fundamentalmente, la de «los sociólogos [...] que dieron su opinión y redactaron la declaración sobre la raza» de 1948/1950. Es frente a ese punto de vista, que «no fue respaldado por la autoridad de aquellos grupos en cuyo sector especial de competencia caen precisamente los problemas biológicos de la raza» que se marcan "diferencias» y «supresiones importantes» (ídem: 38).

A partir de lo expuesto, entendemos pertinente recuperar la noción de contradestinatario propuesta por Eliseo Verón (1987). Desde la perspectiva del sociólogo, la especificidad del discurso político radicaría en un desdoblamiento

${ }^{29}$ En la versión de 1950 esta tercera cita no aparece. 
que se sitúa en la destinación y a partir de la que todo enunciado político es una réplica y anticipa una réplica. Así, junto al prodestinatario (con el que se comparten creencias y valores que se intenta reforzar) y al paradestinatario (al que se intenta persuadir) se presenta una alteridad antagonista. Lo político en el discurso radicaría no en el «marco institucional» de producción de determinada secuencia o en la trayectoria/rol de cierto individuo que la formula, sino en la presentación de una polémica.

Esta definición «no contenidista» y «no institucionalista» resulta muy productiva para nuestro trabajo, pues nos permite analizar la politicidad del discurso más allá de lo que allí se dice y atendiendo cómo se enuncia. Incluso más allá de los resquemores que los autores muestran respecto de esa relación y los peligros de recaer en la "propaganda». En este sentido, se hace palpable una curiosa paradoja. La cuestión de la neutralidad valorativa o de la rigurosidad científica puede (y probablemente, suele) inscribirse en escenas de alto contenido político, si atendemos, justamente, al modo de disposición de voces.

Este tono sostenidamente polémico, que delimita claramente una voz propia (con marcas de primera persona del singular y del plural) y aquellas con las que se confronta, aparece en el documento que servía de prefacio a la declaración de UNESCO de 1951. Ahora bien, curiosamente, la alteridad de dicha disputa está representada, nodalmente, en la figura de los científicos que habían producido la declaración de 1949/1950 («los sociólogos»). Es frente a esas declaraciones que:

Hemos evitado prudentemente toda definición dogmática de raza, pues por ser ésta un producto de factores evolutivos, constituye un concepto dinámico más bien que estático. Con igual prudencia nos hemos abstenido de decir que, puesto que las razas son todas variables y muchas de ellas se superponen mutuamente, hay que concluir que no existen (UNESCO 1969b: 39).

Opera aquí una crítica del estilo «ni.. ... ni» semejante a las que describió Roland Barthes en su texto de mitologías (Barthes, 1990: 80). En ella se objeta la «aplicación errónea» de "la palabra raza» a "las diferencias nacionales, lingüísticas y religiosas», como "deliberado abuso» del término por parte de «los racistas» (ídem: 40). Atendiendo a la necesidad de diferenciarse de esta postura, los científicos se esforzaron en «encontrar una nueva palabra que expresara la misma idea de un grupo biológicamente diferenciado» (ídem). Este esfuerzo posiciona a los científicos firmantes frente a los racistas, pero también frente a la respuesta que, en 1949/1950 había optado por renunciar al concepto en cuestión. El consenso de 1951 es criticar tal posición en nombre de cierta «prudencia» afincada en el sentido común:

El especialista en antropología física, lo mismo que el hombre de la calle, sabe que las razas existen; el primero se basa en las combinaciones de rasgos científicamente reconocibles y mensurables que utiliza para clasificar las variedades de la especie humana; el segundo se basa en el testimonio inmediato de sus sentidos cuando ve un africano, un europeo, un asiático y un indio americano juntos (UNESCO 1969b: 39, énfasis nuestro)

Debe notarse la enorme distancia entres esta formulación y las de la declaración de 1949/1950 que reducían la distinción racial a un mito, o a la 
interpelación de Montagu a no tomarse las categorías de diferenciación racial demasiado en serio. Incluso, en este punto la declaración de 1951 se acerca a posiciones del manifiesto de los científicos de 1938:

La existencia de razas humanas no es una abstracción de la mente, sino que corresponde a una realidad fenoménica, material, perceptible con nuestros sentidos (AA.VV 1938, punto 1: 1)

Justamente, los "sociólogos» de $1949 / 1950$ se habían mostrado particularmente recelosos respecto de la doxa y de aquello que resultaba inmediatamente aprehensible a partir de los sentidos. Desde la perspectiva de estos científicos «nuestras observaciones están, en gran parte, afectadas por nuestros prejuicios» ${ }^{30}$.

Al respecto, resulta interesante indagar en las voces explícitamente dispuestas en la escena enunciativa de la declaración de 1949/1950 como antagonistas (o, en términos de Verón, "contradestinatarios»). Por una parte, en el punto 5 se demarca la alteridad de "la mayoría» ${ }^{31}$ que a pesar de los «hechos científicos» llama «raza» a «todo grupo humano arbitrariamente designado como tal». Más arriba nos hemos referido a otra voz antagónica que aparece demarcada en el documento de 1949/1950, por cierto de un modo quizás sutil:

13. (...) La teoría según la cual caracteres físicos y mentales desfavorables (falta de armonía física y degeneración mental) se manifestarían en los mestizos, jamás ha podido ser comprobada con hechos. No existe, pues, justificación «biológica» para prohibir el matrimonio entre individuos pertenecientes a grupos raciales diferentes (UNESCO 1969a: 34).

Al mismo tiempo que se discute contra aquello que sostienen las perspectivas que objetan el mestizaje, se impugna su caracterización como (legítimamente) biológicas. Las comillas nos indican -como señales- que el enunciador no se siente cómodo con la palabra que mantiene a distancia (Authier, 1984), no se hace responsable de la afirmación que entre ellas se contiene. Nos marca la ajenidad/inadecuación de este adjetivo para describir las justificaciones de la prohibición de los matrimonios interraciales.

En este punto, debemos reintroducir nuestro debate con Taguieff (1992). Según muestra el autor ambas declaraciones insisten en oponerse a la posición de «la doxa» en relación a la cuestión racial. Así, aunque esto es más claro en el documento de 1949/1950 también en 1951 se sostiene que «[l]as diferencias biológicas existentes (...) no pueden en ningún caso justificar las opiniones sobre la desigualdad racial basadas en la ignorancia y los prejuicios» (UNESCO 1969b: 40). A partir de estas expresiones, así como otras presentes en los documentos fundacionales de UNESCO y ciertas prácticas vinculadas a la divulgación de las nuevas «verdades» científicas (vgr. mediante el periódico El correo de la UNESCO) Taguieff concluye que el «interlocutor» de las declaraciones de UNESCO son «las masas» o el "sentido común». Al respecto, caracteriza estas posiciones como inocentes y racionalistas. Ello por varios

\footnotetext{
${ }^{30}$ La traducción literal de la expresión que se utiliza en el texto original en inglés es «lo que se concibe, en buena medida, se preconcibe» («What is conceived is largely preconceived», UNESCO 1949a: 1 ).

${ }^{31}$ En la traducción castellana de 1969 «most people» se traduce como «mucha gente».
} 
motivos. Por un lado, resulta discutible la idea de que el racismo responda a un problema de des/información, educación y prejuicios y que, en este punto, se oponga al verdadero saber, científico. Por otra parte, el autor cuestiona la centralidad que habría adquirido en la discusión de UNESCO cierta vigilancia lingüística que proponía (en particular en 1949/1950) hacer a un lado el uso de la palabra «raza» y sustituirlo por el término «políticamente correcto» de «grupos étnicos».

Tal como queda expuesto hasta aquí, nos interesa proponer otra vía de análisis de las declaraciones de UNESCO. Entendemos que estas representan instancias clave de luchas al interior del campo científico (de múltiples campos, en rigor) y que una de las principales cuestiones en juego era la redefinción de la relación entre ciencia y política. Ello supone un juego más complejo de voces que la oposición analizada Taguieff.

Según analizábamos un poco más arriba, tanto en 1949/1950 como en 1951 además de disputar la "cuestión» racial se discute qué y cómo debe hacer la ciencia frente a ella. En su prudencia y su anti-dogmatismo la declaración de 1951 -aunque advierte frente al «observador superficial» que explica diferencias de temperamentos por diferencias raciales- establece alianzas con la perspectiva del "hombre de la calle» que resultarian inadmisibles para el régimen de enunciación de 1949/1950. De un modo análogo, es menester analizar los procedimientos de atemperación presentes en el documento de 1951, pues ellos resultan en un tono muy distinto al de 1949/1950. Así, por ejemplo, mientras en 1950 se sostenía que "Scientist have reached general agreement in recognising that mankind is one» ("Los científicos han alcanzado un acuerdo general en el reconocimiento de que la especie humana es una») en 1951 se sostiene que "Scientist are generally agreed that all men living today belong to a single species» («Los científicos están generalmente de acuerdo en que todos los hombres que viven hoy pertenecen a una so especie»). En el cuadro a continuación presentamos otras reformulaciones que tienden a «matizar» y «atemperar» las formulaciones asertivas de 1949/1950:

[M]uchas colectividades nacionales, religiosas, geográficas o culturales, debido a la acepción tan amplia que se da a esta palabra, han sido consideradas como "razas», siendo así que, evidentemente, los americanos no constituyen una raza, como tampoco lo son los franceses, los ingleses o los habitantes de cualquier otra nación.

Sea cual fuere la clasificación que el antropólogo hace del hombre, jamás incluye en su clasificación las características mentales
Los grupos nacionales, religiosos, geográficos, lingüísticos y culturales no coinciden necesariamente con los grupos raciales, y los aspectos culturales de estos grupos no tienen ninguna relación demostrable con los caracteres propios de la raza. Los americanos no constituyen una raza, como tampoco los franceses o los alemanes.

La mayor parte de los antropólogos no tienen en cuenta los caracteres mentales en sus clasificaciones de las razas humanas. 
Todos los hechos que han podido reunirse referentes a los cruzamientos de razas comprueban que no han cesado de producirse desde los tiempos más remotos.
No se posee prueba alguna de la existencia de las llamadas razas «puras» (...) En lo que respecta a las mezclas de razas, hay motivos para pensar que el proceso de la hibridación humana, se ha efectuado desde hace un tiempo indeterminado, pero considerable.

Entre ambos documentos opera un notable cambio de registro ${ }^{32}$. Desde la perspectiva de M. Brattain (2007) en la segunda declaración se presupone una lógica falsacionista en la que la hipótesis que debe soportar (infructuosamente) la carga de la prueba es la de la neutralidad de la raza como variable explicativa. Lejos de las vehementes afirmaciones de la primera declaración en la que abunda el uso de un adverbio tan taxativo como «jamás», la declaración de 1951 fomenta un ethos sostenido en la duda como resguardo de la objetividad científica:

Muchos de los miembros de nuestra conferencia creen muy probable que el mestizaje de distintas razas pueda conducir a resultados biológicos ventajosos, aunque no hay suficientes pruebas en apoyo de ninguna conclusión específica (UNESCO 1969b: 40).

Asimismo, Brattain (2007) ha subrayado que mientras en 1949/1950 un solo párrafo había bastado para señalar que los test de inteligencia no podían distinguir entre capacidades innatas y adquiridas y que dadas las mismas oportunidades, todos los grupos tendían a alcanzar resultados equivalentes, el quinto parágrafo de 1951 -dedicado a la misma cuestión- introducía hipótesis contradictorias y paradójicas. Lejos de una toma de posición clara (al estilo 1949/1950) el resultado era, según la misma autora, una «mancha de Rorschach» (2007: 1401). Aunque muchos de los pasajes reforzaban la disyunción entre caracteres mentales y raza, otros resultan más ambiguos:

Es posible -pero no está demostrado- que algunas categorías de aptitudes innatas, de orden intelectual o afectivo, sean más frecuentes en un grupo que en otro; en todo caso, es cierto que estas aptitudes varían tanto, si no más, dentro de un grupo dado que de un grupo a otro. El estudio de la herencia de los caracteres psicológicos presenta múltiples dificultades. Sabemos que algunas enfermedades 0 deficiencias mentales se transmiten de una generación a otra, pero conocemos mal el papel de la herencia en la vida psíquica de individuos normales. (UNESCO 1969b, punto 5: 43, énfasis nuestro)

Entendemos, pues, que los procedimientos de atemperación entre una declaración y la otra son otro de los modos en que opera la crítica que este documento realiza a la declaración de 1949. Así, a las disputas sobre aquello

32 Debemos aclarar que el tono asertivo se mantiene en algunas afirmaciones del documento de 1951 «Jamás se ha establecido por medio de pruebas válidas que esta hibridación haya tenido efectos desfavorables; no existe, pues, ninguna razón biológica para prohibir el matrimonio entre individuos de razas diferentes» (UNESCO 1969b, punto 7: 44, énfasis nuestro). 
que se había afirmado debemos sumar un cuestionamiento respecto del modo en que ello se había realizado. En este proceso también se desmonta la construcción del lugar de «los científicos» que había cristalizado como enunciador (impersonal) de 1949/1950. Tal como hemos señalado, en el prefacio a la declaración de 1951 se afirma que aquel documento había sido resultado, apenas, de «los sociólogos».

Resulta interesante señalar que la construcción imaginaria que los redactores del segundo manifiesto hacen de los firmantes del primero contrasta con el dato en el que coincide toda la historiografía: el alma mater de la declaración de había sido Ashley Montagu, un antropólogo físico que, además, había aportado sus conocimientos en genética poblacional. Por cierto, resulta sugerente que aunque Juan Comas también era un antropólogo físico, la bibliografía haya reparado menos sobre ello.

En cualquier caso, y más allá de la presencia o no de antropólogos físicos en la reunión de 1949, la presentación que propone el documento de 1951 (la declaración «no fue respaldada por la autoridad de aquellos grupos en cuyo sector especial de competencia caen precisamente los problemas biológicos de la raza», ibídem) resulta exitosa en tanto fija aquello sobre lo que debe discutirse y lo establece como evidencia ya-dada: existen los problemas biológicos de la raza ${ }^{33}$. La operación (discursivo/política, agregaríamos) de la declaración de 1949/1950 residía, justamente, en que un panel prioritariamente sociológico -en el que estaban representadas no sólo la voz de uno de los principales sociólogos negros y de la negritud de Estados Unidos, sino también múltiples voces del Sur- puso en cuestión esta evidencia (por ejemplo, con las comillas alrededor de la justificación «biológica»).

Querríamos cerrar este apartado con dos observaciones. Por una parte, resulta sugerente notar que el "retorno» a la mesura, a la prudencia propia de la ciencia (y de la neutralidad científica) que se propone en $1951^{34}$ viene acompañada la puesta en escena de una polémica con todos los rasgos del discurso adversativo-político que retomamos del análisis veroniano. Al respecto, resulta productiva y necesaria la distinción entre el análisis de los objetos imaginarios del discurso («contenido») y los modos de disposición de la escena de enunciación, pues puede haber tensiones entre ambas. El discurso que afirma la neutralidad de la ciencia puede, como es el caso, ser fuertemente polémico y, en ese sentido, político.

En segundo lugar, entendemos que el análisis comparativo entre la relación de las múltiples voces del documento de 1949/1950 y el de 1951 permite interrogar las conclusiones que propone Taguieff (1992). Este autor entiende que la posición de UNESCO redunda en una propuesta de terapéutica semántica e hipercorrección del lenguaje. Probablemente sea el caso. Pero también, hay otra matriz que opera en aquél documento. La tan mentada «razón sociológica». El cuestionamiento radical del "sentido común», de sus

${ }^{33}$ Este tipo de funcionamiento fue analizado por Pêcheux como «elementos preconstruidos», ver Courtine, 1981.

${ }^{34}$ Sin duda se trata de una empresa que fracasó. El texto publicado por UNESCO en que se compaginan las 95 respuestas de los expertos sobre la declaración muestra a las claras la polaridad de las opiniones y la presencia de numerosas posiciones racialistas/racistas entre los expertos respetados del campo. Nos hemos concentrado en esta polémica en otro texto, actualmente en elaboración. 
categorías, de su modo de conocer ¿no es acaso uno de los movimientos clásicos de la sociología? Si este fuera el caso, el debate respecto de la categoría de raza es una discusión por el punto de vista desde el que debe abordarse la «cuestión racial». El documento firmado por Ashley Montagu, Ernest Beagle Hole, Juan Comas, Luis Aguiar Costa Pinto, Morris Grinsbereg, Humayun Kabir y Claude Levi-Strauss sería, sobre todo, una redefinición de este problema en otro terreno, en una nueva escenografía, con formas alternativas de garantías del discurso experto ${ }^{35}$.

\section{Reflexiones finales}

Por bastante tiempo hemos participado de críticas que han pretendido desmontar la «razón imperialista/conquistadora/colonizadora» que operó tras el universalismo de las ciencias sociales de la inmediata posguerra. A partir de ello, hemos hecho de buena parte de sus planteos un blanco relativamente fácil para nuestra impaciencia deconstructiva, que no podía tomarse demasiado en serio la inocencia de sus posiciones (vgr. pretender combatir el racismo combatiendo, simplemente, su lengua). Entendemos que ese tipo de crítica ha subestimado la politicidad y las disputas involucradas en aquellas posiciones y, con frecuencia, ha sobrestimado su propia potencia práctica. Es en el intento de revisar y comprender la politicidad de estas discusiones donde nos interesa inscribir nuestro trabajo. En particular, importa analizar aquellos años que, según entendemos, funcionaron como una suerte de "entretiempo» entre las disputas contra el fascismo y un mundo que se reordenaría bajo las disyunciones de la guerra fría. En el caso de la cuestión racial, interesa analizar la reconfiguración del campo experto en torno de la relación ciencia/política o, también, entre los aspectos descriptivos y los aspectos normativos del discurso científico.

Entendemos que en esa pesquisa resulta nodal la pregunta por aquello con lo que los textos (y las prácticas) analizadas «dialogan» ${ }^{36}$. Al respecto, nos interesa retomar una distinción relevante que trabajó a lo largo del presente artículo, la que distingue entre las condiciones de enunciación y las Condiciones de Formación de determinado documento. Se trata de una diferenciación relevante para un análisis como el que nos proponemos, pues su ausencia podría redundar en la reproducción simple de la escena imaginaria que los textos analizados proyectan y proponen (las voces con las que dicen que discuten).

Según han analizado distintos autores, los procesos de enunciación de una secuencia discursiva (en nuestro caso, de ciertos documentos) ponen en juego una serie de imaginarios respecto de quien enuncia, su posición, la del o los destinatario/s y también sobre el objeto del discurso (Pechêux, 1978). Este juego de imágenes, que opera a nivel textual, construye cierto escenario que es posible analizar como una de las dimensiones de producción de sentidos. Así,

\footnotetext{
${ }^{35}$ Este era, por ejemplo, el principal punto que trató de establecer Franklin Frazier -chairman del encuentro de 1949- en su artículo "Aspectos sociológicos de las relaciones raciales», publicado en el no 8-9 de 1953 de El Correo de la UNESCO. Allí argumentaba que los prejuicios raciales eran sociales y no individuales.

36 En este artículo el «diálogo» incluye la confrontación la obturación, la polémica, el antagonismo, etc.
} 
hemos estudiado algunos aspectos de la disposición de estas escenas, tales como la adjudicación de enunciados a «la ciencia»/«los científicos»/«los sabios» frente a «la mayoría» o, con más mediaciones, a las posiciones asimiladas con «prejuicios o ignorancia».

Ahora bien, más allá de estas formas de disposición de cierta heterogeneidad de voces, toda secuencia "es hablada» por un exterior constitutivo con el que establece un diálogo no marcado, no sabido ni proyectado en la enunciación. Introducir estas otras áreas del discurso al análisis reconfigura los términos de la indagación, pues adquieren espesor todo una serie de relaciones que nos permite comprender mejor los sentidos puestos en juego en una formulación y que no se han tejido allí. La puesta en relación de discursos que no se refieren explícitamente depende de cierto dispositivo de análisis que trabaja sobre huellas textuales. De este trabajo resultan nuevas puestas en serie que permiten descentrar el análisis de la reproducción de los imaginarios a los que nos referimos en el párrafo anterior.

Así, por ejemplo, hemos encontrado analogías no-evidentes respecto del lugar que ocupan «las voces de la calle» o «del hombre común» en el discurso de los científicos fascistas de 1938 y la «vuelta al orden» de 1951. Pero también pueden ponerse en serie formulaciones de 1938 y 1949/1950 si atendemos al tono asertivo y apodíctico que presentan muchos de sus pasajes, y que contrasta con la duda y la vacilación que observábamos en el documento de 1951.

Este trabajo sobre estas resonancias y relaciones resulta central para asir el haz de preguntas que se articulan alrededor de «la cuestión racial» y que organizan el campo de discusiones expertas más allá del eje (fundamental, ineludible) de racismo/anti-racismo. La relación ciencia-política/ciencia-doxa, por ejemplo, se vuelve un tema nodal ante el que la estructura de posicionamientos no necesariamente reproduce la que organiza la contradicción fundamental de la discusión. Atender a estas otras contradicciones, según hemos intentado mostrar, permite, por ejemplo, calibrar el arrojo de la "avanzada» sociológica y de los cientistas del Sur en la declaración 1949/1950, que desplazada del ethos dubitativo-neutral cientificista, hizo del universalismo humanista de la fraternidad y la buena vida ("good life», Montagu, 1979: 122) un lugar para la contraofensiva en un campo en el que aún persistían las posiciones racialistas (incluso encarnadas en las mismas figuras, como fue el caso de C. Gini). Frente a esas posiciones UNESCO se aventuraba:

Finalmente, las investigaciones biológicas vienen a corroborar la ética de la fraternidad universal; porque el hombre es, por tendencia innata, un ser inclinado a la cooperación y, si este instinto no encuentra el modo de satisfacerse, individuos y naciones sufren igualmente sus consecuencias. El hombre es, por naturaleza, un ser social que no llega al pleno desarrollo de su personalidad más que por intercambios con sus semejantes. Todo intento de negar este lazo social entre los hombres es causa de desintegración. En este sentido resulta que todo hombre es guardián de su semejante. Cada ser humano no es más que una porción de la humanidad, a la cual está indisolublemente ligado (UNESCO 1969a: 36). 


\section{Referencias bibliográficas y documentos}

AA.VV (1938), "Razzismo Italiano», La Difesa Della Razza: Scienza, Documentazione, Polemica, año I, nro I, 5 de agosto, 1. Traducción disponible en: https://es.wikipedia.org/wiki/Leyes_raciales_fascistas [Consulta: $10 \mathrm{de}$ agosto de 2015]

Authier-Revuz, J. (1984), « Hétérogénéité(s) énonciative(s)», Langages, 73, 98111.

Barkan, E. (1996), «The politics of the science of race. Ashley Montagu and the UNESCOS's Anti-racist Declarations», en Larry T. Reynolds, Leonard Lieberman (ds.), Race and Other Misadventures: Essays in Honor of Ashley Montagu in His Ninetieth Year, MD Rowman \& Littlefield, Lanham, 96-106.

(1990), «Scientists Against Nazi Racism 1933-1939», en Stocking, George W. (ed.) Bones, Bodies amd Behavior: Essays in Behavioral Anthropology Mobilizing. Univ of Wisconsin Press, Wisconsin, 108-205.

Barthes, R. (1990), Mitologías. Siglo XXI, D.F México.

Brattain, Michele (2007), «Race, Racism, and Antiracism: UNESCO and the Politics of Presenting Science to the Postwar Public», American Historical Review, vol: 112 (5), 1386-1413.

Cassata, F. (2008), La difesa della razza. Politica, ideologia e immagine del razzismo fascista, Einaudi, Torrino.

(2006a), II fascismo razionale. Corrado Gini fra scienza e politica , Carocci editore, Roma. 
(2006b), II Molti, sani e forti. L'eugenetica in Italia, Bollati Boringhieri,

Torino.

Chloé M. (2007), "La question des races ", Gradhiva, 5 | 2007, 114-131. Disponible en : http://gradhiva.revues.org/815 [Consulta: 10 de agosto de 2015]

Courtine, J.J (1981), «Quelques problèmes théoriques et méthodologiques en analyse du discours, à propos du discours communiste adressé aux chrétiens», en Langages, Volumen 15, Número 62, 9-128.

Duedahl, P. (2008), «UNESCO Man: Changing the Concept of Race, 1950-70», American Anthropological Association: 107th Annual Meeting. November 19-23, 2008, San Francisco, California. Disponible en http://vbn.aau.dk/files/61248765/UNESco_Man_Paper_Poul_Duedahl.pdf [Consulta: 10 de agosto de 2015].

Fulanito (2015)

Fulanito et al. (2014)

Gastaut, Y. (2007), " L'UNESCO, les « races » et le racisme », en AA.VV. 60 ans d'histoire de I'UNESCO: actes du colloque international, UNESCO, Paris, 1977-210 Disponible en : http://unesdoc.UNESCO.org/images/0015/001541/154122f.pdf [Consulta: 10 de agosto de 2015].

Germani, A. (2004), Gino Germani: Del antifascismo a la sociología, Taurus, Buenos Aires.

Gil-Riaño, S. (2014), Historicizing Anti-Racism: UNESCO's Campaigns Against Race Prejudice in the 1950s. Tesis Doctoral para el Philosophy Institute for the History and Philosophy of Science and Technology University of Toronto. Disponible en https://tspace.library.utoronto.ca/bitstream/1807/65663/1/gilriano_sebastian_20 1406_PhD_thesis.pdf [Consulta: 10 de agosto de 2015].

Giraudo, L. y Martín-Sánchez, J. (2013), «Dos debates medulares sobre el conceptode raza, 1943-1952», en Revista Mexicana de Sociología, 75,núm. 4 octubre-diciembre, 527-555.

Hazard, A.Q. (2012), Postwar anti-racism: the United States, UNESCO, and race, 1945-1968, Palgrave-Macmillan, New York.

Israel, G. y Natasi, P. (1998), Scienza e razza nll Italia fascista, Societa editrice il Mulino, Bologna.

Maio, M. Ch. (1999), «O projeto UNESCO e a agenda das ciências sociais no Brasil dos anos 40 e 50», RBCS, Vol. 14 no 41 octubre, 141-158.

(2007), « Un programme contre le racisme au lendemain de la Seconde Guerre mondiale ", en AA.VV. 60 ans d'histoire de l'UNESCO: actes du colloque international, UNESCO, Paris, 187-196. Disponible en : http://unesdoc.UNESCO.org/images/0015/001541/154122f.pdf [Consulta: 10 de agosto de 2015]. 
(2000), "The UNESCO Project: Social Sciences and Race Studies in Brazil in the 1950s», en Portuguese Literary and Cultural Studies 4/5, 51-64.

Maiocchi, R. (1999), Scienza italiana e razzismo fascista, La nuova Italia, Firenze.

Métraux, A. (1950), "UNESCO and the racial problem», International social science bulletin, VOL. II, No. 3, Otoño, 384-390.

Montagu, A. (1972), Statement on race. An annotated elaboration and exposition of the four statements on race issued by the UNESCO. Oxford University Press, Londres.

Müller-Wille, S. (2007), « Race et appartenance ethnique : La diversité humaine et l'UNESCO - Les Déclarations sur la race (1950 et 1951)». AA.VV. 60 ans d'histoire de l'UNESCO: actes du colloque international, UNESCO, París, 211221. Disponible en : http://unesdoc.UNESCO.org/images/0015/001541/154122f.pdf [Consulta: 10 de agosto de 2015].

Pêcheux, M. (1978), "Las condiciones de producción del discurso », en Hacia el análisis automático del discurso, Gredos, Madrid, 44-61.

(2012). "Leitura e memória: Projeto de Pesquisa», en Eni Puccinelli Orlandi Análise de Discurso. Textos escolhidos, Pontes, Campinas, SP, 141150.

Pisanty , V. (comp.) (2007), La «difesa della razza»: antologia 1938-1943.

Tascabili Bompiani , Milan

Prins, H. y Krebs, E. (2007), " Vers un monde sans mal : Alfred Métraux, un anthropologue à l'UNESCO (1946-1962)", en AA.VV. 60 ans d'histoire de I'UNESCO: actes du colloque international, UNESCO, París, 115-126. Disponible en : http://unesdoc.uNESCO.org/images/0015/001541/154122f.pdf [Consulta: 10 de agosto de 2015].

Taguieff, P. A. (1992), «Du racisme au mot « race » : comment les éliminer ? ». Mot, Volumen 33, Número 33, 215-239.

Servi, S. (2005) «Building a Racial State: Images of the Jew in the Illustrated Fascist Magazine, La Difesa della Razza, 1938-1943», en Joshua Zimmerman (comp.) Jews in Italy under fascist and nazi rule, 1922-1945, Cambridge University Press, Cambridge, 114-157.

UNESCO (1949a) «Statement on Race. Meeting of experts on Race Problems. UNESCO House 12-14 December 1949. UNESCO/SS/Conf.1/6. Paris, 28 December 1949». Disponible en http://unesdoc.UNESCO.org/images/0015/001569/156945eb.pdf [Consulta: 10 de agosto de 2015].

UNESCO (1949b) «Summary report (of the six meetings). Dec. 1949-Feb. 1950. SS/CONF.1/SR.1-6». Disponible en : http://unesdoc.UNESCO.org/images/0015/001569/156983eb.pdf [Consulta: 10 de agosto de 2015]. 
UNESCO (1949c) «Working paper of the Committee. 20 Jan. 1950.SS/CONF.1/3 " Disponible en : http://unesdoc.UNESCO.org/images/0015/001569/156970eb.pdf [Consulta: 10 de agosto de 2015].

UNESCO (1951) «Statement on the nature of race and race differences; by physical anthropologists and geneticists, June 1951. WS/111.69» Disponible en: http://unesdoc.UNESCO.org/images/0015/001577/157730eb.pdf [Consulta: 10 de agosto de 2015].

UNESCO (1952) The Race concept: results of an inquiry, UNESCO, París Disponible en: http://unesdoc.UNESCo.org/images/0007/000733/073351eo.pdf [Consulta: 10 de agosto de 2015].

UNESCO (1969a) «Declaración sobre la raza, París, julio de 1950». UNESCO Cuatro declaraciones sobre la cuestión racial, UNESCO, París, 31-37. Disponible en: http://unesdoc.UNESCO.org/images/0012/001281/128133so.pdf [Consulta: 10 de agosto de 2015].

UNESCO (1969b) «Declaración sobre la naturaleza de la raza y las diferencias raciales, París, junio de 1951» 38. UNESCO Cuatro declaraciones sobre la cuestión racial, UNESCO, París, 38-46. Disponible en: http://unesdoc.UNESCO.org/images/0012/001281/128133so.pdf [Consulta: 10 de agosto de 2015].

Vallejos, G. (2012), «Roma: capital de un Imperio bajo el signo de la biología política (1936-1942)», Dynamis vol.32 no.1 Granada, Barcelona 32 (1): 115140. Disponible en: http://scielo.isciii.es/scielo.php?pid=S021195362012000100006\&script=sci_arttext [Consulta: 10 de agosto de 2015]

Verón, E. (1987), «La palabra adversativa», En AA.VV. El discurso político. Hachette, Buenos Aires, 11-26. 